\title{
VICO Y LA ESTRATEGIA RACIONALISTA
}

\author{
Alberto M. DAMIANI \\ Universidad de Buenos Aires
}

1. La compleja relación que Giambattista Vico (1668-1744) mantiene con el racionalismo moderno no puede reducirse a fórmulas esquemáticas. En primer lugar, Vico no considera al racionalismo como un bloque homogéneo, sino que distingue sutilmente entre sus distintos representantes y formula argumentos diferentes respecto de distintas tesis de cada uno de ellos. En segundo lugar, el juicio viquiano sobre el racionalismo no se mantiene inalterado a lo largo de todos sus escritos. Una comparación de los argumentos formulados en distintas obras de Vico permite apreciar las substantivas variaciones de la posición del filósofo napolitano sobre el moderno racionalismo.

La reconstrucción de un cuadro medianamente completo de la relación de Vico con el racionalismo moderno, que cuente con suficiente base textual, es una tarea todavía pendiente de la crítica especializada. Si se acota el marco de referencia a algunos representantes destacados del moderno racionalismo esta tarea no resulta menos ardua. La dificultad resulta patente si se consideran, por ejemplo, los argumentos que aparecen en las distintas obras de Vico sobre diversas tesis de René Descartes y de Hugo Grocio. Puede advertirse, por un lado que los diversos argumentos viquianos referentes a la filosofía cartesiana mantienen entre sí un alto grado de independencia recíproca y, por el otro, que Vico modifica sustancialmente su juicio sobre la iusfilosofía de Grocio.

Dentro de la crítica de Vico a la filosofía de René Descartes pueden distinguirse, al menos, cuatro argumentos independientes. El primero se refiere la idea cartesiana de la introducción del método geométrico en física. Vico impugna esta idea afirmando que una mente sólo puede conocer su propia 
obra (verum ipsum factum). El segundo argumento se refiera a la condena que las exigencias cartesianas de la evidencia intuitiva y el método geométrico hacen pesar sobre las humanidades. Vico impugna esta idea afirmando la necesidad de aplicar el arte de descubrir (tópica) antes del arte de juzgar (crítica). El tercer argumento se refiere a las posibles consecuencias políticas de la recepción de la filosofía cartesiana. Aunque el propio Descartes pretenda evitarlo mediante la idea de una moral provisional, Vico advierte que cierto racionalismo político aplica imprudentemente el juicio científico a la toma de decisiones políticas. Por último, el cuarto argumento, se refiere al criterio de verdad cartesiano. Vico lo impugna afirmando que las afirmaciones evidentes no constituyen una refutación del escepticismo ${ }^{1}$.

El análisis del juicio viquiano sobre la iusfilosofía de Grocio también conduce a un cuadro altamente diferenciado. Por un lado, en su Vita scritta da se medesimo, Vico reconoce a Grocio como el "quarto autore" que, después de Platón, Tácito, y Francis Bacon, habría influido decisivamente en su formación. Por el otro, Vico identifica a Grocio, junto a Samuel Pufendorf y John Selden, entre los representantes de la escuela moderna del derecho natural que su Scienza Nuova pretende refutar ${ }^{2}$.

Por lo que antecede, puede advertirse que la relación de Vico con el racionalismo moderno y, más específicamente, con las filosofías de Descartes y de Grocio no puede aprehenderse mediante formulas simplificadoras. Sin embargo, el objetivo general de las críticas viquianas al racionalismo puede aclararse si se atiende al juicio de Vico respecto de las pretensiones racionalistas de haber refutado definitivamente al escepticismo. Este juicio aparece explícitamente formulado en el Liber metaphysicus, donde Vico objeta el criterio de verdad cartesiano y en la Scienza Nuova, donde rechaza la doctrina del derecho natural propuesta por Hugo Grocio. Estas críticas tienen una interesante peculiaridad, que permite comprender la especial relación que mantiene el filósofo napolitano con el racionalismo moderno. En ambos casos, Vico comparte el objetivo de refutar al escepticismo pero pone en cuestión la estrategia raciona-

1 Una reconstrucción de estos cuatro argumentos anticartesianos de Vico aparecerá en: Alberto M. Damiani, "Las críticas de Vico a Descartes", Cuadernos de filosofia, Universidad de Buenos Aires, ; y en: Alberto M. DamiAni; Giambattista Vico. La ciencia anticartesiana, Buenos Aires, Almagesto, en prensa.

2 Sobre esta aparente paradoja de la lectura viquiana de Grocio véase: Guido FASsò, Vico e Grozio, Napoli, Guida, 1971. 
lista para llevar a cabo dicho objetivo. A los ojos de Vico, los argumentos de Descartes y de Grocio no alcanzan para refutar al escéptico Carnéades. Vico no trata al racionalismo como un adversario sino un aliado al que es necesario corregir.

El propósito de este trabajo es presentar una reconstrucción de dos argumentos que Vico enuncia contra la estrategia racionalista para refutar el escepticismo. El primero se refiere al criterio de verdad postulado por René Descartes y a su pretensión de refutar al escepticismo en el plano metafísicognoseológico. El segundo trata sobre la doctrina del derecho natural de Hugo Grocio y a su pretensión de refutar al escepticismo en el plano jurídico-político. Para cumplir con este propósito se mostrará que ambos argumentos de Vico contienen tres momentos: (a) demostrar que el argumento racionalista no refuta al escepticismo; (b) conceder a los escépticos las razones que oponen al argumento racionalista y (c) refutar al escepticismo partiendo de estas razones.

Frente a la representación corriente de Vico como un filósofo irracionalista, se pretende demostrar aquí que Vico coincide con el objetivo racionalista de refutar a los escépticos y que sus objeciones al racionalismo se dirigen exclusivamente a la estrategia racionalista para cumplir con ese objetivo.

2. En el apartado $3 .^{\circ}$ del capítulo uno del libro primero (Liber metaphysicus) de De antiquissima italorum sapientia ex linguae latinae originibus eruenda $(1710)^{3}$, Vico cuestiona la estrategia cartesiana para refutar a los escépticos. Estos sostienen que el ser humano es incapaz de lograr conocimiento verdadero y que la búsqueda de un conocimiento imposible para la mente humana conduce al hombre a la infelicidad. Descartes pretende haber refutado a los escépticos al indicar que la afirmación "pienso» es indudable ${ }^{4}$. Esta pretensión depende de la identificación de la verdad con la certeza indudable. El argumento cartesiano podría presentarse bajo la siguiente forma: Toda afirmación indudable o cierta es verdadera, la afirmación "pienso" es indudable, entonces la afirmación "pienso" es verdadera. Según Descartes, el escéptico debería verse obligado a admitir que conoce al menos

3 Cf. Giambattista Vico, Liber Metaphisicus. Risposte, München, Wilhelm Fink Verlag, 1979, pp. 48-52. (en adelante: LM, 48-52).

4 Cf. René DescarTes, Discours de la Métode IV y Les Meditations Metaphysiques II, en: Oeuvres, vols. VI y IX, ed. Ch. Adam \& P. Tannery, París, Leopold Cerf, 1897-1910. 
una afirmación verdadera y con ello quedaría refutada la tesis que niega al ser humano la facultad de conocer la verdad. La estrategia racionalista para refutar a los escépticos depende, en este caso, de la identificación de la certeza con la verdad.

(a) Vico intenta demostrar que el argumento cartesiano no refuta a los escépticos. Para nuestro autor, los escépticos podrían, sin cometer contradicción alguna, admitir que la afirmación "pienso" es absolutamente indudable y rechazar que el ser humano sea capaz de obtener conocimiento verdadero. Ello sería posible con sólo negarse a admitir la premisa "toda afirmación indudable o cierta es verdadera». Las razones que podría alegar el escéptico para rechazar esta premisa serían todos los contraejemplos, recabables de nuestra experiencia, en los que una afirmación nos parece absolutamente indudable y luego nos vemos obligados a reconocer que resulta ser falsa. Estos contraejemplos serían, para Vico, razón suficiente para rechazar la identificación cartesiana de certeza y verdad.

Vico pretende demostrar que la certeza del cogito no puede hacerse valer frente a un escéptico consecuente. Según Vico, ante el recurso cartesiano al carácter indudable del cogito, el escéptico siempre podría alegar lo siguiente: "dado que muchas veces lo falso nos parece cierto e indudable, la certeza no puede admitirse como criterio de verdad. No hay razones para admitir que la afirmación "pienso" es verdadera, a pesar de que me resulte absolutamente indudable». Vico advierte que si la afirmación "pienso" no contiene la prueba de que la mente humana es capaz de obtener conocimiento verdadero, no contiene tampoco la refutación del escepticismo pretendida por Descartes. Por ello, sería necesario rechazar la estrategia cartesiana para refutar a escepticismo y concentrarse en una estrategia de refutación alternativa.

(b) Vico concede a los escépticos las razones que éstos podrían oponer al argumento racionalista, admitiendo que la certeza debe distinguirse de la verdad. La distinción entre verum y certum cobrará particular relevancia en el Diritto Universale y en la Scienza Nuova. La primera formulación viquiana de esta distinción aparece en el Liber metaphysicus atribuida a los escépticos. A juicio de Vico, éstos siempre podrían recurrir a esta legítima distinción para responder a la estrategia racionalista de refutación. Vico asume como propia la distinción entre verum y certum, atribuida a los escépticos, y la lleva hasta sus últimas consecuencias. 
Atendiendo a la argumentación viquiana formulada en el Liber metaphysicus y en el Diritto Universale 5 , la diferencia semántica ente verum y certum podría reconstruirse del siguiente modo. El término "certeza» se refiere a una relación posible entre la conciencia y sus representaciones. Decimos que una representación es "cierta" para una conciencia, cuando ésta se cree incapaz de cuestionarla. El termino "verdad», en cambio, se refiere a una posible relación entre una representación y el objeto representado. Decimos que una representación es «verdadera» cuando refleja fielmente el objeto que representa. Por lo tanto, la predicación del adjetivo "certum" respecto de una representación no implica necesariamente la predicación del adjetivo "verum» y viceversa. A juicio de Vico, la idea de certeza debe distinguirse de la idea de verdad porque la incapacidad de una conciencia para dudar de una representación no garantiza la fidelidad con que esta representación refleja al objeto representado. Aquella incapacidad caracteriza a la certeza y no tiene conexión alguna con esta fidelidad.

Partiendo de esta distinción semántica entre certum y verum, Vico establece la distinción entre conscientia y scientia. Mientras que la certeza es una afección de la conciencia, la verdad es una propiedad de la ciencia. Las representaciones científicas son verdaderas porque contienen los principios (o causas) que permiten crear los objetos representados. Este concepto de scientia supone que si la representación de un objeto contiene las causas del mismo, dicha representación refleja fielmente al objeto y puede afirmarse que es verdadera. El escéptico diseñado por Vico atribuye al ser humano la conciencia de certezas pero le niega el conocimiento de verdades científicas.

5 Cf. GlambatTISTa VICO, De universi iuris uno principio et fine uno liber unus, De opera proloquium, $\$ 30$ : «Duo verba sunt verum et certum, quae distingui oportet, uti falsum omnes distinguunt a dubio: quare quantum distat a dubio falsum, tantum distet a vero certum. Quae duae res nisi statuantur aliae, cum multa vera sint dubia, ea essent dubia et certa simul; et contra, cum innumera falsa pro certis habeantur, ea falsa simul et vera essent".

El propio Vico conecta este fragmento del De Uno (1720) con el argumento formulado en el Liber metaphysicus (1710), al insertar, después de "oportet", una llamada a pie de página que dice: "Uti nos praestitimus in primo libro De antiquissima italorum sapientia ex linguae latinae originibus eruenda, qui Metaphysicam complectitur" (GLAmbaTTISTA VICO, Il Diritto Universale, a cura di Fausto NiCOLINI, Bari, Laterza, 1936, p. 35). Esta llamada a pie de página debe hacerse valer contra la postulación de una presunta ruptura entre el Liber metaphysicus y el De Uno, postulada por Guido FASSO en: "The Problem of Law and the Historical Origin of the New Science", en: Giorgio TAGliacozzo and Donald Phillip Verene (eds.), Giambattista Vico's Science of Humanity, Baltimore and London, The Johns Hopkins University Press, 1976, pp. 3-14. 
La mente humana podría tener certeza de los efectos pero sería incapaz de conocer las causas.

Volviendo al problema del cogito, Vico sostiene que aún cuando el escéptico es consciente de que piensa, ignora tanto las causas del pensar como el modo en que se produce el pensamiento ${ }^{6}$. Vico concede a los escépticos la distinción entre certeza y verdad que les permite responder a la estrategia racionalista. La contrapartida que Vico obtiene de esta concesión es la explicitación de las noción escéptica de «scientia». Esta noción es la clave de la estrategia adoptada por Vico para refutar al escepticismo metafísic-gnoseológico.

(c) Vico intenta refutar a los escépticos partiendo de las razones que éstos oponen al argumento racionalista. Para desentenderse del fallido intento de refutación racionalista, el argumento escéptico se basa en la distinción conceptual entre la certeza y la verdad o entre la conciencia y la ciencia. Esta distinción presupone una concepción del conocimiento científico verdadero: conocimiento de las causas o de los principios que permiten crear el objeto conocido. El escepticismo sostiene que la mente humana es incapaz de este conocimiento porque carece de los principios que permiten crear cualquier objeto, esto es tanto el mondo físico como la mente humana misma.

En el $4 .^{\circ}$ apartado del primer capítulo del Liber metaphysicus, Vico utiliza esta concepción escéptica del conocimiento científico verdadero para refutar al escepticismo (Cf. LM, 54). Si se le concede al escéptico que el conocimiento científico de un objeto es el conocimiento de las causas o principios que permiten crearlo, el escéptico deberá admitir que una mente siempre es capaz de conocer científicamente su propia obra, porque contiene los principios o causas con que esa obra fue creada. Por lo tanto, la identificación de una obra atribuible exclusivamente a la mente humana sería suficiente, a juicio de Vico, para refutar al escepticismo. Si la mente humana es autora de una obra, contiene los principios o causas de la misma que permiten formar una fiel representación de la misma.

Vico concibe los objetos de la matemática como una obra creada exclusivamente por la mente humana. La mente humana conoce stricto sensu las verdades matemáticas, porque crea los elementos y los principios con los que

6 «At, quamquam conscius sit scepticus se cogitare, ignorat tamen cogitationis caussas, sive quo pacto cogitatio fiat»: LM, 50 . 
compone los objetos matemáticas. Mediante el contraejemplo del conocimiento matemático, Vico pretende refutar a los escépticos partiendo de presupuestos epistemológicos escépticos. Si el escéptico identifica al conocimiento científico verdadero con el conocimiento de las causas, se equivoca al negarle a la mente humana la capacidad para conocer científicamente; porque si bien la mente humana no es autora de la naturaleza ni de si misma, sí es autora de los objetos estudiados por la matemática. En el plano metafísico-gnoseológico, la refutación viquiana del escepticismo tendría la siguiente forma: si la mente humana contiene los principios o causas que le permiten crear los objetos matemáticos y estos principios le permiten conocerlos de modo verdadero, entonces el escepticismo queda refutado.

La noción de scientia que Vico atribuye a los escépticos es, por un lado, el punto de partida de la estrategia viquiana de refutación del escepticismo, alternativa a la desechada estrategia racionalista, y por el otro el núcleo del principio epistemológico verum ipsum factum con que Vico fundamentará, a partir de 1730, la posibilidad de una Scienza Nuova sobre la naturaleza común de las naciones ${ }^{7}$.

3. En las distintas ediciones de los Principi di una Scienza Nuova (1725, $1730,1744)$ Vico cuestiona la estrategia adoptada por Hugo Grocio para refutar a los escépticos en el campo jurídico-político ${ }^{8}$. Estos sostienen que el derecho se reduce a un conjunto de convenciones aceptadas voluntariamente por los miembros de una comunidad política; que la amenaza del uso de la fuerza es el medio más eficaz para lograr el consentimiento y que la utilidad es el motor exclusivo de la acción humana. En el plano jurídico-político, el escéptico diseñado por Grocio rechazaría la idea de un derecho natural, obligatorio para todo el género humano, independiente del asentimiento voluntario y derivado de la razón humana. Grocio pretende haber refutado a los escépticos al indicar que las normas del derecho positivo (iuris voluntarium humanum)

7 Giambattista VICO, Principi di una Scienza Nuova d'intorno alla comune natura delle nazioni, in questa terza impressione dal medesimo autore in gran numero di luoghi Corretta, Schiarita, e notabilmente Accresciuta. (1744), ed. Andra BATTISTINI, Opere, Milano, Mondadori, 1990, vol 1, $\$ 331,349$ (en adelante: SN, 331, 349).

8 Cf. Hugo Grocio, De iure belli ac pacis libri tres, in quibus jus naturae et gentium, item iuris publici praecipua explicantur (1680), Prolegomena, $\$ \$ 5-8$, en: id. Del derecho de presa. Del derecho de la guerra y de la paz, ed bilingüe, trad. P. M. GOMEZ, Madrid, Centro de Estudios Constitucionales, 1987, pp. 32-36. 
obedecidas por los súbditos de las distintas naciones -únicas normas reconocidas por los escépticos- presuponen la observancia de un conjunto de normas universales, dictadas por la recta razón (dictatum rectae rationis) e independientes del consentimiento humano. Por ejemplo la norma «se deben cumplir los pactos" se encontraría implícitamente admitida por quienes establecen cualquier convención. Por otra parte, Grocio sostiene que la satisfacción de la utilidad privada - único móvil de la acción humana, según los escépticospresupone la satisfacción del deseo de vivir en una sociedad pacífica y organizada con arreglo al entendimiento (appettitus societatis).

La pretensión grociana de refutar al escepticismo depende, por tanto, de la postulación de un motor de la acción humana distinto de la utilidad privada. Según Grocio, el escéptico debería verse obligado a admitir que las normas del derecho voluntario humano presuponen las del derecho natural y que la satisfacción de la utilidad privada presupone la satisfacción del deseo de vivir en sociedad, propio de la naturaleza humana. Con ello quedaría refutada, a juicio de Grocio, la tesis escéptica que niega la posibilidad de fundamentar racionalmente el derecho voluntario humano o positivo.

(a) Vico intenta demostrar que el argumento de Grocio no refuta a los escépticos (cf. SN, 135). Según Vico, estos podrían admitir que los seres humanos desean vivir en sociedad, sin atribuir este deseo a una supuesta naturaleza humana y podrían admitir también que la idea de que una convención presupone siempre la expectativa de su cumplimiento, sin reconocer que esta expectativa se deduce de una norma del derecho natural reconocida necesariamente por la razón humana.

A juicio de Vico, la estrategia racionalista de Hugo Grocio sería ineficaz contra el escéptico que redujese la satisfacción del deseo de vivir en sociedad a un simple medio para la persecución de la utilidad privada y que concibiese la norma que exige el cumplimiento de las promesas como a una parte del significado de la expresión "convención voluntaria». Las razones que podría alegar el escéptico se centrarían en la imposibilidad de constatar empíricamente un deseo gregario independiente de la utilidad privada y en la ineficacia de un presunto derecho natural independiente de las normas del derecho positivo (ius voluntarium humanum), que rige en las diversas comunidades políticas.

El argumento del escéptico podría reconstruirse del siguiente modo: dado que si existe un deseo gregario, nunca se opone a la utilidad privada y si existe un derecho natural, se encuentra ya siempre presupuesto en el derecho postivo, 
entonces la postulación de un deseo gregario y de un derecho natural resulta superflua. Esta postulación racionalista significaría, para el escéptico, una multiplicación innecesaria de la cantidad de entes. Si fuese posible reducir por un lado el presunto deseo gregario (alegado por Grocio contra los escépticos) a un medio de la utilidad privada y por el otro, las supuestas normas del derecho natural (distinguidas por Grocio del derecho voluntario) a explicitaciones analíticas del significado de cualquier convención, entonces la estrategia del racionalismo jurídico-político no lograría refutar a los escépticos. A juicio de Vico, los argumentos de Grocio no son suficientes para que Carnéades se vea obligado a admitir el dictatum rectae rationis, que contendría las normas universales del derecho natural y el appettitus societatis, que garantizaría la sociabilidad de la naturaleza humana. Por ello, Vico cree necesario rechazar la estrategia racionalista adoptada por Grocio para refutar al escepticismo jurídico-político atribuido a Carnéades y concentrarse en una estrategia de refutación alternativa.

(b) Vico concede a los escépticos las razones que éstos oponen al argumento racionalista, admitiendo por un lado que la utilidad privada es el único móvil de la acción humana y por el otro que la idea de un derecho natural racional no puede servir como guía ni como parámetro de las primeras instituciones económicas y civiles, porque la racionalidad es un resultado tardío en el curso histórico que recorren las naciones. Respecto de la idea de utilidad privada como único móvil de la acción humana el argumento viquiano podría presentarse del siguiente modo. Dado el ser humano tiene una «naturaleza corrupta», sus acciones voluntarias se dirigen casi exclusivamente a la satisfacción egoísta de sus necesidades y a la búsqueda de lo que cada uno cree útil para sí mismo (Cf. SN, 341). La necesidad y la utilidad serían, según Vico, las "dos fuentes del derecho natural de las gentes" (SN, 141). Como consecuencia del pecado original, el ser humano se desentendería de todo deseo gregario en favor del interés egoísta, resultando inapropiada la postulación racionalista de un presunto appettitus societatis ${ }^{9}$. A juicio de Vico, el establecimiento de instituciones sociales y políticas no sería más que un resultado involuntario de

9 Por ello Vico acusa a Grocio de sostener la "ipotesi sociniana del (...) uomo semplicione». Cf. GiambatTista Vico, Principi di una Scienza Nuova intorno alla comune natura delle nazioni per la quale si ritruovano i principi di altro sistema del diritto naturale delll genti (1725), ed. Andrea BATTISTINI, Opere, cit., vol II, $\$ \$ 16,47,134,482$ (En adelante: SNP, 16, 47, 134, 482); Giambattista VICO, Lettera a Monsignor Filippo Maria Monti, Opere I, cit., p 306; SN, $338,553$. 
acciones humanas voluntarias, tendientes a lograr exclusivamente objetivos autointeresados (CF. SN, 1008).

Por otra parte, Vico también concede a los escépticos que la autoridad y la certeza del derecho positivo, establecido en las diversas comunidades políticas, no depende de una comprensión racional de las normas del derecho natural. Según Vico, la idea perfecta de justicia - que los racionalistas pretenden deducir de la idea abstracta de naturaleza humana- sólo puede surgir bajo determinadas condiciones institucionales. Las religiones y las leyes educarían la mente humana hasta el punto en que ésta sea capaz de concebir la idea perfecta de justicia (CF. SNP, 15-22). Los racionalistas proyectarían ilegítimamente esta idea, tardíamente concebida por la mente humana, sobre su representación de los autores del mundo civil, a los que imaginarían como "hombres iluminados por la razón natural completamente desplegada» (SN, 394). Por lo tanto, Vico admitiría que los escépticos tienen razones suficientes para rechazar los postulados racionalistas de un deseo de asociación (appettitus societatis) y de un derecho racional independiente de la voluntad (dictatum rectae rationis) atribuibles a la naturaleza humana. Vico concede a los escépticos que la utilidad privada es el móvil exclusivo de la acción humana y que las normas del derecho voluntario humano obedecidas por los autores de las distintas naciones no dependen de un presunto conjunto de normas jurídicas naturales aprehensibles por la razón pura de cualquier miembro del género humano. La contrapartida que Vico obtiene de esta concesión es la explicitación de los presupuestos subyacentes a las nociones escépticas de «utilidad privada» y de "derecho voluntario". Estas nociones son las claves de la estrategia adoptada por Vico para refutar al escepticismo jurídico-político.

(c) Vico intenta refutar a los escépticos partiendo de las razones que éstos oponen al argumento racionalista. Para desentenderse del fallido intento de refutación iusnaturalista, el argumento escéptico sostendría que resulta superfluo postular intereses gregarios y derechos naturales, porque éstos sólo se encarnarían en intereses egoístas y en convenciones voluntarias. Este argumento presupone que las instituciones se reducen a medios para satisfacer fines egoístas o que la utilidad es la causa del derecho. La representación escéptica de una institución consiste en una convergencia más o menos armónica de voluntades autointeresadas.

Vico señala a los escépticos la dificultad de justificar esta representación de la naturaleza de las instituciones. Una vez rechazados los postulados racionalistas, 
resultaría problemático suponer que un agregado de voluntades autointeresadas puedan establecer y conservar una institución social o política. Sin las ideas grocianas de appettitus societatis y de dictatum rectae rationis, no parece haber motivos suficientes para suponer que las voluntades autointeresadas, por si mismas y libradas a sus propias dinámicas, lograrán establecer y conservar convenciones. Un escepticismo consecuente implicaría una concepción descarnada de los intereses egoístas que impediría formarse cualquier ilusión respecto del establecimiento y conservación de las instituciones. Frente a los escépticos, Vico parece advertir que si las instituciones fuesen sólo medios para satisfacer intereses egoístas, convenciones dependientes de voluntades autointeresadas, serían sólo acuerdos precarios e inseguros que no permitirían la conservación del género humano en la tierra ${ }^{10}$.

A juicio de nuestro autor, los escépticos habrían interpretado incorrectamente el axioma que califica a las necesidades y utilidades de "fuentes" del derecho. Según Vico, los intereses egoístas serían sólo ocasiones (o razones necesarias) para el establecimiento de las instituciones pero no causas (o razones suficientes) para su establecimiento ${ }^{11}$. Contra la reducción escéptica de las instituciones a meros medios de satisfacción de intereses egoístas, Vico sostiene que el intento de satisfacer estos intereses sería un medio para el establecimiento de instituciones. Estas garantizarían la conservación del género humano en la tierra porque siempre le procurarían a los seres humanos lo que necesitan, aunque no siempre le procuren lo que quieren (cf. SN, 1008).

Por lo tanto, Vico pretende refutar a los escépticos partiendo de presupuestos antropológicos y jurídicos escépticos. Si la utilidad privada es el único móvil de la acción humana, el derecho no puede reducirse a una convención voluntariamente establecida, sino que debe encarnar también fines no buscados por los autores del mundo civil. Contra lo que suponen los escépticos,

10 Vico presenta en su descripción del stato ferino la situación a la que habría conducido la "libre" divergencia de las voluntades autointeresadas. Véase: SN, 369.

11 En el Diritto Universale, Vico atribuye también a Grocio la opinión escéptica de que la utilidad es la causa del derecho. Esta atribución resulta sorprendente, porque Grocio había intentado explícitamente refutar esa opinión, que él atribuía al escéptico Carnéades. CF. GIAMbatTISTA VICO, De universi iuris uno principio et fine uno liber unus, XLVI, I, Il Diritto Universale, parte prima, cit., pp. 54-55 ; Hugo Grocio, De iure belli ac pacis, cit. $\$ 16$. Sobre este temprano error, no repetido en obras posteriores, de la lectura viquiana de Grocio véase: Guido Fassó, Vico e Grozio, cit., p. 44. 
Vico pretende haber demostrado que la «constantia iurisprudentiae» supone la exstencia de un derecho natural de las gentes, no reductible a las convenciones voluntarias del derecho positivo.

4. Si resultan admisibles las reconstrucciones de los argumentos viquianos presentadas más arriba, resulta evidente que no puede confundirse a Vico con un adversario del racionalismo moderno. Por el contrario, las críticas de Vico a Descartes y a Grocio pretenden ser la introducción a una estrategia alternativa para enfrentar al adversario natural del racionalismo: Carnéades, el escéptico. Vico comparte con Descartes la exigencia de fundamentar metafísicamente la capacidad de conocimiento humano y con Grocio la de fundamentar filosóficamente el derecho; esto es comparte los problemas, los objetivos y las tareas planteadas por los racionalistas del siglo XVII, pero pretende formular mejores respuestas presentando nuevos medios para cumplir esos objetivos y maneras más eficaces de realizar esas tareas. Tanto respecto del racionalismo metafísico de René Descartes como respecto del racionalismo jurídico-político de Hugo Grocio, la presentación de las debilidades del argumento racionalista y las concesiones a los escépticos son sólo un medio para refutar definitivamente al escepticismo. 